\title{
A Study of 8 Patients with Polycythaemia Vera: The Impact of JAK2 (V617F) Mutation on Diagnosis
}

\author{
M.B. Ino-Ekanem ${ }^{1}$, I.A. Ibanga ${ }^{2, *}$ and E.H. Jumbo ${ }^{1}$ \\ ${ }^{1}$ Department of Haematology, University of Uyo Teaching Hospital, Uyo, Akwa Ibom State, Nigeria \\ ${ }^{2}$ Department of Haematology, University of Calabar Teaching Hospital, Calabar, Cross River State, Nigeria
}

\begin{abstract}
Background: The discovery of the Janus Kinase 2 (JAK2) gene mutation provides a new molecular approach for the diagnosis of polycythaemia vera (PV).

We studied retrospectively patients with a diagnosis of PV at initial presentation to the hospital. They were followed up for an initial period of 2 months.

Objective: The objectives were to access the clinicopathological characteristics, impact of identification of JAK2 mutation on diagnosis and treatment strategies.

Result: Of the 6 patients with complete medical records, 3 were males $(50 \%)$. The mean haematocrit values were $59.7 \%$, males had a value of $60.3 \%$ while females a values of $59.0 \%$. The total WBC count was $8.8 \times 10^{9} / \mathrm{L}$ while the platelet count was $463.5 \times 10^{9} / \mathrm{L}$. None of the patients' had splenomegaly, all had pruritus. During follow up the mean haematocrit values were $52.3 \%$, males had a value of $55.8 \%$ while females a values of $48.7 \%$. The total WBC count was $11.1 \times 10^{9} / \mathrm{L}$ while the platelet count was $652.1 \times 10^{9} / \mathrm{L}$. There was a reduction in the haematocrit value but the white blood cell and platelet counts remained high.

Of the 5 patients who had molecular analysis done, $4(80 \%)$ had the JAK2 mutation while in $1(20 \%)$ the mutation was not detected. The results of the molecular analysis done in a regional laboratory were received after an average of 21 days.

The patients were treated with phlebotomy and hydroxyurea. One patient with increasing thrombocytosis had clopidogrel initiated. 3 patients were lost in the follow-up period once there was clinical improvement, at 6 months and 1 year only 1 patient was left in follow-up.
\end{abstract}

Conclusion: The lag time for obtaining results of molecular analysis was long, which made diagnosis and management on clinicalbasis.

This highlights the need for the upgrading of more laboratories to acquire molecular technology for improved patients care and diagnostic accuracy.

Keywords: Polycythaemia vera, JAK2 mutation, Clinicopathological diagnosis, UUTH, Nigeria.

\section{INTRODUCTION}

Chronic myeloproliferative disorders polycythaemia vera $(P V)$, essential thrombocythaemia $(E T)$ and primary myelofibrosis (PMF) are now called myeloproliferative neoplasm's (MPNs) by the $4^{\text {th }}$ edition of the WHO classification of haemopoietic tumors [1]. They are disorders due to the clonal proliferation of a multipotential haemopoietic stem cell with normal maturation and a tendency for extramedullary haemopoiesis. Beyond these characteristics, PV, ET and PMF share more in common genotypically and phenotypically with each other than with the other MPNs [2-5]. The tendency for each to acquire the phenotypic characteristics of the other makes it worth asking whether they are separate disorders, different manifestation of the same disease or combination of

"Address correspondence to this author at the Department of Haematology University of Calabar Teaching Hospital, Calabar, Nigeria;

Tel: +2348037108216;

Email: iquoibanga@gmail.com, iquoibanga@unical.edu.ng both. The current molecular evidence supports the last possibility [6]. Their initial clinical presentations are also highly variable and are subject to change overtime.

In PV also termed polycythaemia rubra vera, there is increased erythrocyte mass, the blood, bone marrow spleen and liver are variably involved during progression through 2 disease phase, a proliferative or polycythaemic phase with increased red cells and a post polycythaemic or spent phase with marked cytopenias, extramedullary haemopoiesis, hypersplenism and myelofibrosis. A subset may transform to acute leukemia.

Haemorrhage, thrombosis and hyperviscosity represent the primary clinical manifestations. Thrombotic events include stroke, Deep vein thrombosis, Myocardial infarction, Budd - Chiari syndrome [7]. Bleeding complications include epistaxis, oral mucosal bleeding, gastrointestinal haemorrhages, non- specific ecchymoses. Hyperviscosity syndromes 
from sludging of blood flow and micro thrombi may cause hypertension, headache, dizziness, visual disturbances vertigo, tinnitus, claudication and erythromelagia. Pruritus classically described following exposure to warm water results from histamine release from activated basophils and mast cells.

The eligibility criteria for PV were originally created by the Polycythaemia Vera Study Group known as the PVSG diagnostic criteria. The combination of their recommended major and minor criteria (Table 1) remained the gold standard for several decades [8]. In 2001 the WHO classification of PV was published (Table 2). This classification included a modernized approach to diagnosis by adding several new laboratory studies, the classification also aimed at applying the Revised European - American lymphoma (REAL) classification which was successfully used for lymphoid and myeloid neoplasm's to MPDs [9].

The discovery of JAK2 and MPL genetic mutations provided new insights into the molecular basis of MPDs [10-13]. In 2007 there was a revision in the $4^{\text {th }}$ edition of the WHO diagnostic criteria for MPDS to reflect this
$[6,14]$. The objective of identification of JAK 2 mutation in patients with clinical manifestation suggestive of PV was aimed at diagnostic accuracy, to facilitate targeted pharmacotherapeutics and prevent disease progression.

\section{PATIENTS AND METHODS}

\section{Study Population}

The data used were from the medical records of the 8 patients that a diagnosis of $\mathrm{PV}$ was made by Consultant Haematologists in the University of Uyo Teaching Hospital after reviewing the history, physical signs and laboratory investigations in accordance to the PVSG diagnostic criteria, from January 2008 December 2015. The follow-up period was two, six months and 1year. Two patient's record were incomplete therefore were excluded.

Permission was sought and obtained in written form from the Head of Medical Records Department after obtaining Ethical clearance from the Hospital's Ethical committee.

\section{Table 1: PVSG Diagnostic Criteria for PV}

\begin{tabular}{|l|l|}
\hline Major Criteria & $\begin{array}{l}\text { 1. Total red blood cell mass- In males, } \geq 36 \mathrm{ml} / \mathrm{kg} ; \text { in females } \geq 32 \mathrm{ml} / \mathrm{kg} . \\
\text { 2. Arterial oxygen saturation } \geq 92 \% . \\
\text { 3. Splenomegaly. }\end{array}$ \\
Minor Criteria & $\begin{array}{l}\text { 1. Thrombocytosis with platelet count }>400,000 / \mathrm{uL} . \\
\text { 2. Leukocytosis with a white blood cell count }>12,000 / \mathrm{uL} . \\
\text { 3. Increased leukocyte alkaline phosphatase }>100 \mathrm{U} / \mathrm{L} .\end{array}$ \\
4. Serum vit. B12 concentration $>900 \mathrm{pg} / \mathrm{ml}$ or binding capacity $>2200 \mathrm{pg} / \mathrm{ml}$.
\end{tabular}

*Diagnosis of PV is established with all major criteria or first 2 major criteria plus any 2 minor criteria.

Table 2: WHO Diagnostic Criteria for PV

\begin{tabular}{|l|l|}
\hline A1 & Elevated RBC mass $>25 \%$ above mean normal predicted value, or $\mathrm{Hb}>18.5 \mathrm{~g} / \mathrm{dl}$ in men, 16.5g/dl in women. \\
\hline A2 & $\begin{array}{l}\text { No cause of secondary erythrocytosis, including absence of familial erythrocytosis; no elevated erythropoietin due to } \\
\left.\text { hypoxia (arterial } \mathrm{PO}_{2}<92 \%\right), \text { high oxygen affinity haemoglobin, truncated erythropoietin receptor, inappropriate } \\
\text { erythropoietin production by tumor. }\end{array}$ \\
\hline A3 & Splenomegaly. \\
\hline A4 & Clonal genetic abnormality other than $\mathrm{Ph}$ chromosome or BCL/ABL fusion gene in marrow cells. \\
\hline A5 & Endogenous erythroid colony formation in vitro. \\
\hline B1 & Thrombocytosis $>400 \times 10^{9} / \mathrm{L}$. \\
\hline B2 & WBC count $>12 \times 10^{9} / \mathrm{L}$. \\
\hline B3 & Bone marrow biopsy showing pan myelosis with prominent erythroid and megakaryocytic proliferation. \\
\hline B4 & Low serum EPO levels \\
\hline
\end{tabular}

${ }^{*} \mathrm{PV}$ is diagnosed when $\mathrm{A} 1+\mathrm{A} 2$ +any other $\mathrm{A}$ or $\mathrm{A} 1+\mathrm{A} 2+$ any $2 \mathrm{~B}$. RBC indicates red blood cell, $\mathrm{Hb}$, haemoglobin; Ph, Philadelphia; WBC, white blood cell; EPO, erythropoietin. 
Records from the Haematology clinic and Haematology Laboratory registers were used to authenticate clinic attendance and the laboratory results obtained. The JAK2 mutation was analyzed at Safety Molecular Laboratory, Owerri, Nigeria, a regional reference laboratory using allele specific Polymerase chain reaction (PCR).

\section{RESULTS}

Table 3. shows the demographic and clinical characteristics of the patients at diagnosis and during the 2 months follow up period. There were 8 patients at entry, 2 patients had to be excluded due to poor records during follow up. $3(50 \%)$ patients were males while $3(50 \%)$ were females. The mean age at diagnosis was 57.5 years, 3(50\%) were above 60 years. The mean haematocrit was $59.0 \%$ and $52.3 \%$ at diagnosis and follow up respectively. For males it was $60.3 \%$ and $55.8 \%$ at diagnosis and follow up while females had $59.0 \%$ and $48.7 \%$ respectively.

The total WBC counts $8.8 \times 10^{9} / \mathrm{L}$ and $11.1 \times 10^{9} / \mathrm{I}$ at diagnosis and follow up with $5(83.3 \%)$ patients having values below $11 \times 10^{9} / \mathrm{L}$. The mean platelet count was $463.5 \times 10^{9} / \mathrm{L}$ at diagnosis rising to $652.1 \times$ $10^{9} / \mathrm{L}$ during follow up. $4(66.7 \%)$ patients had platelets $>400 \times 10^{9} / \mathrm{L}$ at diagnosis while $5(83.3 \%)$ had during follow up.

There was no splenomegaly in any of the patients while all had pruritus and conjunctival suffusion. There was no thrombotic event at diagnosis; one patient had a persistent rising thrombocytosis. $3(50 \%)$ patients defaulted once there was clinical improvement. At 6 months and 1 year there was only one patient left in

Table 3: Demographic and Clinical Characteristics of Patients at Diagnosis and during Follow up

\begin{tabular}{|c|c|c|}
\hline Variables & Patients at Diagnosis & Patients In Follow Up \\
\hline No of patients No (\%) & $6(100)$ & $6(100)$ \\
\hline Male sex No (\%) & $3(50)$ & $3(50)$ \\
\hline Female sex No (\%) & $3(50)$ & $3(50)$ \\
\hline Mean Age at diagnosis (yrs) & 57.5 & - \\
\hline$\leq 60$ & $3(50)$ & - \\
\hline$\leq 60$ & $3(50)$ & - \\
\hline Mean Haematocrit (\%) & 59.7 & 52.3 \\
\hline Male & 60.3 & 55.8 \\
\hline Female & 59.0 & 48.7 \\
\hline Mean WBC count $\times 10^{9} / \mathrm{L}$ & 8.8 & 11.1 \\
\hline$\leq 11$ & $5(83.3)$ & $5(83.3)$ \\
\hline$\geq 11$ & $1(16.7)$ & $1(16.7)$ \\
\hline Mean Platelet $\times 10^{9} / \mathrm{L}$ & 463.5 & 652.1 \\
\hline$\leq 400$ & $2(33.3)$ & $1(16.7)$ \\
\hline$\geq 400$ & $4(66.7)$ & $5(83.3)$ \\
\hline Splenomegaly & Nil & Nil \\
\hline Thrombotic event & Nil & $1(16.7)$ \\
\hline Pruritus & $6(100)$ & Nil \\
\hline Conjunctival suffusion & $6(100)$ & Nil \\
\hline JAK2 Mutation & $4(66.7)$ & \\
\hline Time for obtaining Result in days & 21 & \\
\hline \multicolumn{3}{|l|}{ Disease Outcome } \\
\hline Left treatment facility & & $3(50)$ \\
\hline Still in follow up & & $3(50)$ \\
\hline Death & & Nil \\
\hline
\end{tabular}


follow up. The average time it took for results of JAK2 analysis to arrive at treatment facility was 21 days.

\section{DISCUSSION}

The prevalence of PV in the study area was $6.3 \%$ [15]. In the study in Benin, Nigeria with a larger population size, the prevalence was $1.4 \%$ [16]. There was none recorded in the study done in Ilorin, Nigeria [17]. Due to the lack of large population based studies in a disease of low frequency [18], the prevalence of $\mathrm{PV}$ is not well documented. In a unique study in Connecticut, USA using health claim records and applying it to the entire population of the state, the agestandardized prevalence of 22 per 100,000 was obtained, and is similar to the Italian and Swedish studies [19]. The lower frequencies in the studies in developing countries needs to be further analyzed in a larger multi-centered study program. In this study there are 3 males $(50 \%)$ and 3 females $(50 \%)$ at presentation, the mean haematocrit value was $59.7 \%$. The males had a value of $60.3 \%$ while in females it was $59 \%$. There was no statistical significant difference. This absence of statistical difference may be age related as most of the females were above 60 years.

In the follow up patients there was a significant reduction $(P<0.01)$ in the haematocrit value to $52.3 \%$. The males and females had a value of $55.8 \%$ and $48.7 \%$ respectively. This was in response to phlebotomy.

The tWBC at presentation was $8.8 \times 10^{9} / \mathrm{L}$ and there was a progressive increase to $11.1 \times 10^{9} / \mathrm{L}$ in the follow up period despite initiation of hydroxurea a cytoreductive therapy.

The platelet count at presentation was $463.5 \times 10^{9} / \mathrm{L}$ with a statistical significant increase to $652.1 \times 10^{9} / \mathrm{L}$ in the follow up $(P<0.001)$ despite the cytoreductive therapy. The persistence and rising thrombocytosis necessitated the addition of clopidogrel an anti-platelet drugs in one of the patient. Acetylsalicylic acid was used for the other patients in the follow-up period.

The average time for obtaining the results of the JAK2 analysis was 21 days; this is outside the time it takes to educate and counsel the patient's family to bear the cost of the test. Applied in this manner the identification of JAK2 mutation may only improve diagnostic accuracy. The initiation of targeted pharmacotherapeutics with anti-JAK2 properties would have been of benefit to the patient's outcome as rising
WBC counts and platelet counts are risk factors for thrombotic events [20].

\section{CONCLUSION}

The impact of the identification of JAK2 mutation in patients with PV- like symptoms offers diagnostic accuracy but needs to be readily available and affordable to improve the quality of management of cancer patients in developing countries.

\section{ACKNOWLEDGEMENTS}

None of the authors declare any conflict of interest or any competing financial interests. We are grateful to the Resident doctors in the Department of Haematology, University of Uyo, Akwalbom State for their commitment to documentation.

\section{REFERENCES}

[1] Ola Landgren, Lynn R Goldin, Sigurdur Y Kristinsson, Elin A Helgadottir, Jan Samuelsson and Magnus Bjorkholn. Increased risk of Polycythaemia Vera, Essential Thrombocythaemia and Myelofibrosis among 24577 first degree relatives of 11039 patients with Myeloproliferative neoplasms in Sweden. Blood 2008; 112(6): 2199-2204. https://doi.org/10.1182/blood-2008-03-143602

[2] Jerry L Spivak, Micheal Considine, Donna M Williams, Conover C Talbot Jr, Ophelia Rogers, Alison R Moliterno, ChunfaJie and Micheal F Ochs. Two Clinical Phenotypes in Polycythemia Vera. The New EngL J of Med 2014; 371(9): 808-817.

https://doi.org/10.1056/NEJMoa1403141

[3] Muhammad Shariq Shaikh, Mohammad Usman Shaikh, Salman Naseem Adil, Mohammad Khurshid, Zeehan Ansar Ahmed. Clinico-Pathology profile and outcomes of patients with Polycythaemia Vera, Essential Thrombocythaemia and Idiopathic Myelofibrosis: A Tertiary Care Centre Experience from Southern Pakistan. J Ayub Med Coll Abbottabad 2016; 28(2): 293-297.

[4] Tiong IS, Casolari DA, Nuguyen T, Van Velzen MJM, Ambler $\mathrm{K}$, D'Andra RJ et al. Masked PV is genetically intermediate between JAK2V617F mutated essential thrombocythaemia and overt polycythemia vera. Blood Cancer J 2016. 6, e 459: doi10. 1038/bcj. 2016.70

[5] Grzegorz Helbig, Agata Wieczorkiewicz, Malgorzata Krawczyk, Darusz Kata, Marek Seweryn, Wlodzimierz Mendrek et al. The JAK2 V617F point mutation correlates with clinical phenotype in patients with polycythemia vera and essential thrombocythemia contemporary oncology 2008; 12 (10): 452-454.

[6] Jerry L Spivak and Richard T Silver. The revised World Health Organization diagnostic criteria for polycythaemiavera, essential thrombocytosis, and primary myelofibrosis: an alternative proposal. Blood 2008; 112(2): 231-238. https://doi.org/10.1182/blood-2007-12-128454

[7] Koushik Gudavalli, Shilpa Chikati, Mohan R Jakkamputi, Kamal L Behera, Swarne LD Gambir. An Uncommon presentation of Polycythemia Vera as Ischemic Stroke - A Rare Case Report. International J of Scientific Research 2014; 3(5): 455-457. https://doi.org/10.15373/22778179/MAY2014/144 
[8] Ming Cao, Randell J Olsen, Youli Zu Polycythaemia Vera, New Clinicopathologic Perspective. Arch Pathol Lab Med 2006; 130: 1126-1132.

[9] Michiels JJ, Bernema Z, Van Bockstaele D, De Raeve H, Schroyens W. Current diagnostic criteria for the Chronic myeloproliferative disorders (MPD) essential thrombocythemia (ET), Polycythemia Vera (PV) and Chronic idiopathic myelofibrosis CIMF. Pathol Biol 2007; 55(2): 92104

https://doi.org/10.1016/j.patbio.2006.06.002

[10] Jong-Ha Yoo, Tae Sung Park, Ho-Young Maeng, Young-Kyu Sun, Young-Ah Kim, Joeng-HaeKie et al. JAK2 V617F/C618R Mutation in a Patient with PV: A case study and review of Literature. Cancer genet. cytogenet 2008.09.010 dio.org/10.1016/

[11] Yu - Min Yeh, Yi - Lin Chen, Hsieh -Yin Cheng, Wu - Chou Su, Nan - Haw Chow, Tsai - Yun Chen et al. High percentage of JAK2 Exon 12 mutation in Asian Patients with Polycythemia Vera. Am. J Clin Pathol 2010; 134: 266-270. https://doi.org/10.1309/AJCPK7KGOWPHYWM0

[12] Linda M Scott, Wei Tong, Ross L Levire, Mike A Scott et al. JAK2 Exon 12 mutation in PV and Idiopathic Erythrocytosis. N. Engl. J Med 2007; 356: 459-468. https://doi.org/10.1056/NEJMoa065202

[13] Leonardo Caires dos Santos, Juliana Correa da Costa Ribeiro, Neusa Pereira Silva, Janete Cerutti, Maria Regina Regis da Silva, Maria De Lourdes Lopes Ferrari Chauffaille. Cytogenetics, JAK2 and MPL mutations in PV, Primary Myelofibrosis and essential thrombocythemia. Rev Bras Hematol Hemoter 2011; 33(6): 417-424. https://doi.org/10.5581/1516-8484.20110116

[14] James W Vardiman, Juergen Thiele, Daniel a. Arber, Richard D Brunning, Micheal J Borowit ${ }_{2}$, Anna Porwit et al. The 2008 revision of World Health Organization (WHO) classification of the myeloid neoplasms and acute leukaemia: rational and important changes. Blood 2009; 114: 937-951.

https://doi.org/10.1182/blood-2009-03-209262

[15] Akpan IS, Ekanem AM. Pattern of Haematological Malignancies among Adult Nigerians Attending a Tertiary Hospital in South south Nigerian: Eight years Review. W. J Biomed Res 2016; 3(1): 17-23.

[16] NIA A OO, B GN, H NKD, O CE. The Epidemiology of Haematological Malignancies at the University of Benin Teaching Hospital: A Ten- year Retrospective Study. The Internet Journal of Epidemiology 2010; 9 (2):

[17] Babatunde A, Amiwero C, Olatunji P, Durotoye I. Pattern of Hematological Malignancies in Ilorin, Nigeria: A ten year Review. The Internet Journal of Haematology 2008; 5 (2). ispub- article13470.

[18] Baruch Modan. An epidermiological study of Polycythemia Vera. Blood 1965; 26(5): 657-667.

[19] Xiaomei Ma, Gary Vanasse, Brenda Cartmel, Yun Wangand $\mathrm{H}$. Andrew Selinger. Prevalence of polycythemia vera and essential thrombocythemia. Am. J of Haematol 2008; 83: 359-362. https://doi.org/10.1002/ajh.21129

[20] Passamonti F, Rumi E, Pietra D, Boveri E, Arcaini L, Roncoroni $\mathrm{E}$ et al. A prospective study of 338 patients with Polycythaemiavera: The impact of JAK2 (V617F) allele burden and leukocytosis on fibrotic or leukemic disease transformation and vascular complications. Leukemia 2010; 24: 1574-1579. https://doi.org/10.1038/leu.2010.148 (http://creativecommons.org/licenses/by-nc/3.0/), which permits unrestricted, non-commercial use, distribution and reproduction in any medium, provided the work is properly cited. 